\title{
Produção de Forragem de Capim-Elefante sob Clima Frio. 2. Produção e Seletividade Animal ${ }^{1}$
}

\author{
Miguel Dall'Agnol'2, Simone Meredith Scheffer-Basso ${ }^{3}$, \\ João Antonio L. do Nascimento ${ }^{4}$, Carlos Alberto Miranda Silveira ${ }^{4}$, Ricardo G. Fischer ${ }^{4}$
}

\begin{abstract}
RESUMO - Foram comparadas, neste estudo, a produção e a seletividade animal de cultivares de capim-elefante em condições de clima frio, em Lages, Santa Catarina. O ensaio constou de 12 cultivares (Mineiro X-23A, Mineiro, Taiwan A-144, CAC-262, Mole da Volta Grande, Teresópolis, Vrukwona, Merckeron Pinda, Turrialba, Porto Rico, Taiwan A-14 e Cameroon), estabelecidas em parcelas de $17,5 \mathrm{~m}^{2}$, em um delineamento de blocos casualizados, com três repetições. Cada parcela foi formada por sete linhas espaçadas 0,50 m, considerando-se como área útil as três linhas centrais. Os cortes para avaliação da produção de forragem foram realizados em janeiro, março e maio de 1985 e 1986, sempre que as plantas atingiram cerca de 1,5 m de estatura. A avaliação da seletividade animal foi realizada em janeiro e março de 1987, após o pastoreio, mediante notas atribuídas ao resíduo de forragem na parcela (método Botanal). A análise da variância mostrou efeito significativo de anos e de cultivares para a produção total de forragem, não havendo efeito significativo para a interação desses fatores. Na média dos dois anos, o potencial de produção variou entre 11 e 21 t MS/ha. Observou-se uma redução de $27 \%$ na produção de forragem no segundo ano, com média geral dos cultivares de $12.116 \mathrm{~kg}$ MS/ha, que foi significativamente inferior à do ano anterior (16.662 kg MS/ha). O cv. Mineiro X-23A foi o que apresentou a maior produção de forragem, superando $20 \mathrm{t}$ MS/ha. O cv. Porto Rico destacou-se pela maior proporção de folhas e maior seletividade pelos animais e o cv. CAC-262, pela maior estabilidade, ou seja, menor variância nos dois anos de avaliação.
\end{abstract}

Palavras-chave: adaptação, persistência, seletividade

\section{Elephantgrass Forage Yield under Cold Climate Conditions. 2. Production and Animal Selectivity}

\begin{abstract}
This work was aimed to compare the production and animal selectivity of elephant grass cultivars in the cold conditions, of Southern Brasil (Lages, Santa Catarina). Twelve cultivars of elephantgrass were used (Mineiro X-23A, Mineiro, Taiwan A-144, CAC-262, Mole da Volta Grande, Teresópolis, Vrukwona, Merckeron Pinda, Turrialba, Porto Rico, Taiwan A-148 and Cameroon), established on $17.5 \mathrm{~m}^{2}$ plots in a randomized block design, with three replicates. Each plot consisted of seven lines with $0,50 \mathrm{~m}$ interval, using the tree central lines for measurements. These measurements were made on January, March and May of 1985 and 1986, each time the plants height reached $1.5 \mathrm{~m}$. The animal selectivity was done on January and March of 1987, giving scores to the forage after grazing the plots (Botanal method). There was a significant effect of years and cultivars on total forage yield, but the interaction was not significant. On the average, the yield potential ranged from 11 to $21 \mathrm{t} \mathrm{DM} /$ ha. There was a $27 \%$ reduction on forage yield on the second year (12,116 $\mathrm{kg} \mathrm{DM} /$ ha of average), compared with the first year (16,662 kg DM/ha). The cultivar Mineiro X-23A presented the highest forage yield and the cultivar Porto Rico showed the highest proportion of leaves and animal selectivity and the cultivar CAC-262 the highest stability, presenting a smaller variance on the two years of evaluations.
\end{abstract}

Key Words: adaptation, persistence, selectivity

\section{Introdução}

O capim-elefante (Pennisetum purpureum Schum.) é uma importante forrageira tropical utilizada nas regiões tropicais para produção de carne e leite. Há um número relativamente grande de cultivares de capim-elefante, cujo potencial forrageiro é bem conhecido e estreitamente relacionado à sua adaptação às condições edafoclimáticas locais e práticas de manejo (Tcacenco \& Botrel, 1990).

A grande quantidade de cultivares dessa espécie se deve à introdução de um mesmo genótipo em diversos locais, sem que a identificação original seja mantida (Daher et al., 1997). Segundo Otero (1961), no início da utilização do capim-elefante, no Brasil,

\footnotetext{
1 Trabalho financiado pela EPAGRI, Governo do Estado de Santa Catarina.

2 Eng. Agr., PhD, Professor da Universidade Federal do Rio Grande do Sul, bolsista CNPq. Ex-Pesquisador EPAGRI, E.E. de Lages.

${ }^{3}$ Eng. Agr., Dra., Professora da Universidade de Passo Fundo, RS (simone@upf.tche.br).

${ }^{4}$ Eng. Agr., MSc., Ex-Pesquisadores EPAGRI, E.E. de Lages.
} 
havia apenas dois cultivares: o cv. Napier, com colmos grossos e lâminas largas e o cv. Merker, com colmos finos e lâminas estreitas.

No Brasil, os trabalhos com essa espécie se concentram nas regiões Centro-Oeste, Nordeste e Sudeste, onde o manejo e a avaliação de cultivares estão consolidados, principalmente nos estados de Minas Gerais e São Paulo. O modelo brasileiro conhecido como "Piracicaba", instalado na década de 70, preconiza o uso intensivo de capim-elefante no período de máximo crescimento, com elevadas doses de nitrogênio (Assis, 1997). No entanto, essas regiões são bastante distintas do Sul do Brasil, sobretudo as regiões de maior altitude, onde ocorrem temperaturas mais frias, o que impossibilita a transferência direta da tecnologia gerada naquelas condições. Para o estado de Santa Catarina, um dos poucos registros publicados cita produções médias de $5 \mathrm{t} \mathrm{MS/ha/ano} \mathrm{(Vetterle} \mathrm{\&}$ Salerno, 1983), obtidas em ensaios conduzidos em Itajaí, no litoral de Santa Catarina, onde prevalecem temperaturas mais elevadas em relação às regiões serranas.

O receio em se cultivar essa gramínea nas regiões de maior altitude de Santa Catarina e Rio Grande do Sul está evidentemente vinculado à ocorrência de invernos rigorosos e, em algumas regiões, com geadas já no outono. Skerman e Riveros (1992) apontam $15^{\circ} \mathrm{C}$ como a temperatura mínima para o crescimento do capim-elefante, sendo que a temperatura mínima média do mês mais frio está na faixa de $11,5 \pm 4,4^{\circ} \mathrm{C}$. No Planalto Catarinense, onde está situado o município de Lages, as temperaturas no mês mais frio oscilam de $-3^{\circ} \mathrm{C}$ a $18^{\circ} \mathrm{C}$ (Gonçalves, 1990), o que limita o período de crescimento da maioria das espécies estivais em quatro a cinco meses no ano.

Jacques (1990) defende o cultivo do capim-elefante mesmo em regiões frias, em virtude de seu elevado potencial forrageiro no período primaveraverão, uma vez que existem diferenças entre cultivares para tolerância ao frio, o que pode ser explorado em trabalhos regionais. Para o Rio Grande do Sul, Westphalen (1975) indica como regiões preferenciais para o cultivo dessa espécie aquelas com temperaturas mínimas superiores a $10^{\circ} \mathrm{C}$.

Considerando a total ausência de informações na região, foram avaliados a produção e o grau de seletividade pelos animais de doze cultivares de capim-elefante, em Lages, no período de 1985-1987, visando identificar os mais promissores.

\section{Material e Métodos}

O trabalho constou da avaliação de doze cultivares de capim-elefante (Mineiro X-23A, Mineiro, Taiwan A-144, CAC-262, Mole da Volta Grande, Teresópolis, Vrukwona, Merckeron Pinda, Turrialba, Porto Rico, Taiwan A-148, Cameroon), nos anos de 1985, 1986 e 1987, na Estação Experimental de Lages, pertencente à Empresa Catarinense de Pesquisa e Extensão Rural (Epagri), em Lages, na região do Planalto de Santa Catarina, situada a uma latitude de $27^{\circ} 49^{\prime}$, longitude de $50^{\circ} 20^{\prime}$ e altitude de $937 \mathrm{~m}$. O clima é chuvoso e se caracteriza por invernos e verões amenos (Cfb), segundo classificação de Köppen. Os dados de temperatura e precipitação mensais e as normais constam na Figura 1.

Os cultivares foram estabelecidos em parcelas de $17,5 \mathrm{~m}^{2}$, em um delineamento de blocos casualizados, com três repetições, em dezembro de 1983. Cada parcela foi formada por sete linhas espaçadas de $0,50 \mathrm{~m}$, considerando-se como área útil as três linhas centrais. O plantio foi feito por meio de mudas, colocadas horizontalmente em sulcos, a uma profundidade média de $20 \mathrm{~cm}$. O solo da área experimental pertence à Unidade de Mapeamento Lages e consiste em um cambissol húmico distrófico álico de textura argilosa. O solo foi corrigido e adubado de acordo com o

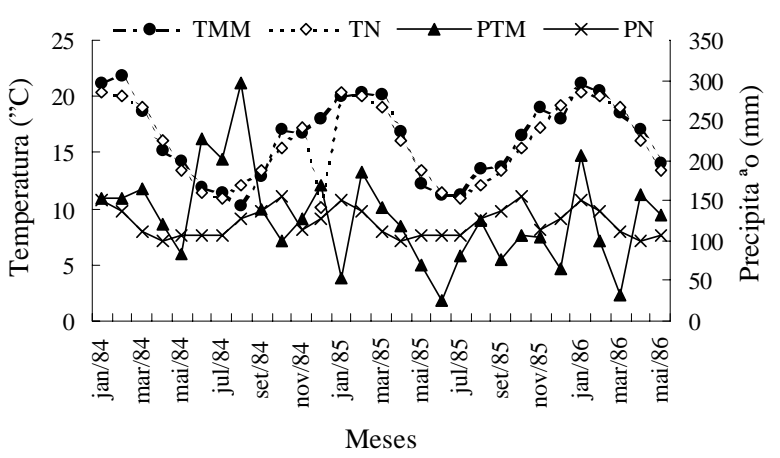

Figura 1 - Temperaturas médias mensais (TMM), temperaturas normais (TN), precipitação mensal (PTM) e precipitação normal (PN) no período entre o estabelecimento e o último corte. Fonte: Estação Meteorológica de Lages, Santa Catarina.

Figure 1 - Mean monthly temperatures (MT), normal temperatures (NT), monthly rainfall (MTR) and normal rainfall $(N R)$ in the period from establisment to the last cut. Source: Meteorological Station, Lages, Santa Catarina. 
resultado da análise química. Após um ano, em outubro de 1984, foi realizada nova análise do solo, que registrou os seguintes dados: $\mathrm{pH}=6,2 ; \mathrm{P}=4,5 \mathrm{mg} / \mathrm{L}$; $\mathrm{K}=45 \mathrm{mg} / \mathrm{L}$. Em novembro desse ano, foram aplicados $120 \mathrm{~kg}$ de $\mathrm{P}_{2} \mathrm{O}_{5}$, na forma de superfosfato triplo (SFT), e $720 \mathrm{~kg}$ de $\mathrm{K}_{2} \mathrm{O}$, na forma de cloreto de potássio $(\mathrm{KCl})$, fracionado em duas vezes. No ano de 1985, foram realizadas duas adubações de manutenção: em março, foram aplicados $120 \mathrm{~kg}$ de $\mathrm{P}_{2} \mathrm{O}_{5}$, na forma de SFT, $720 \mathrm{~kg}$ de $\mathrm{K}_{2} \mathrm{O}$, na forma de $(\mathrm{KCl})$ e $45 \mathrm{~kg} \mathrm{~N} / \mathrm{ha}$, na forma de uréia; em novembro, $60 \mathrm{~kg}$ $\mathrm{P}_{2} \mathrm{O}_{5}$ e $720 \mathrm{~kg}$ de $\mathrm{K}_{2} \mathrm{O}$. Como regra, após cada corte, foi realizada uma adubação nitrogenada com $22,5 \mathrm{~kg}$ N/ha, na forma de uréia.

Os cortes para avaliação da produção de forragem foram realizados manualmente, sendo que, no primeiro ano, a média esteve em 1,4 m e, no segundo, em 1,2 m. Em 1985, os cortes ocorreram em 10/1, 12/3 e 3/5 e em 1986, em 8/1, 5/3 e 13/5. Imediatamente antes do corte, foi estimada a estatura media do dossel; em seguida, as plantas foram cortadas com foices e o material verde foi pesado e amostrado, para determinação do teor de matéria seca, realizada por meio de secagem em estufa a $70^{\circ} \mathrm{C}$, até peso constante.

Após dois anos de avaliação da produção de forragem, foi realizada uma avaliação da seletividade pelos animais (Hodgson, 1979), em janeiro e março de 1987, mediante notas atribuídas após o pastoreio, a partir da estimativa visual de três observadores (método Botanal). As notas variaram de 1 a 5 , considerando-se, respectivamente, $1=100 \mathrm{~g}, 2=325 \mathrm{~g}, 3=550 \mathrm{~g}$, $4=775 \mathrm{~g}$ e $5=1000 \mathrm{~g}$ de resíduo verde em cada amostra de $0,25 \mathrm{~m}^{2} /$ parcela, de forma que as maiores notas indicam menor seletividade pelos animais. O pastoreio foi feito com dez vacas secas da raça Holandesa, com peso vivo médio de $450 \mathrm{~kg}$. Determinou-se o número de animais necessários para consumir todo o material disponível em cada repetição durante três a quatro dias, tomando-se por base a média das produções de forragem dos genótipos nos dois ciclos anteriores de avaliação, ou seja, os animais tinham acesso a uma repetição por vez e somente eram colocados na repetição seguinte após terem consumido toda a forragem disponível dessa repetição. Essas avaliações ocorreram entre 12 e 26 de janeiro de 1987 e entre 23 de março a 7 de abril de 1987, quando a maioria dos cultivares atingiram 1,5 m. Fez-se o pastejo de cada repetição isoladamente, em sequiência numérica crescente, da primeira para a terceira repetição, no primeiro período, invertendo-se a ordem no segundo período. Com esse procedimento, procurou-se manter o mesmo intervalo de tempo na avaliação de cada repetição. Após o pastejo de toda a área experimental, procedeu-se a um corte de emparelhamento, deixandose um resíduo de 15 a $20 \mathrm{~cm}$.

Os dados foram submetidos à análise da variância, por intermédio do modelo de parcela subdividida no tempo, no qual os cultivares constituíram a parcela principal e os anos, as subparcelas. As médias, quando comprovado o efeito significativo dos tratamentos, foram comparadas pelo teste Tukey a $5 \%$ de significância. Posteriormente, foi realizada uma análise de estabilidade e adaptabilidade segundo o modelo de Eberhart \& Russel (1966), considerando-se todos os cortes realizados ao longo dos dois anos, por intermédio do programa estatístico SAS.

\section{Resultados e Discussão}

A análise de variância comprovou efeito de anos e de cultivares para a produção total de forragem dos dois anos e do total de cada ano, não havendo efeito significativo para a interação desses fatores. O cv. Mineiro X-23A foi o que apresentou a maior média de produção de forragem, com 21,5 t MS/ha, destacando-se como o de maior produção nos dois anos (Tabela 1). No ano de 1985, as produções variaram de 12 a 14 t MS/ha, e no ano seguinte, de 8 a 18 t MS/ ha, com amplitude média de cerca de $10 \mathrm{t} \mathrm{MS} / \mathrm{ha}$ entre a maior e a menor produção.

No segundo ano, houve, na média geral de produção de forragem, redução de $27 \%$ na produção, o que pode ser parcialmente atribuído à menor precipitação ocorrida nesse período, bem inferior às normais (Figura 1). Em outros trabalhos com cultivares de capim-elefante, realizados em regiões quentes, também têm sido verificadas variações no desempenho produtivo, com reduções no ano subseqüente ao estabelecimento. Mozzer et al. (1970), na Zona da Mata, Minas Gerais, verificaram a superioridade do cv. Mineiro (17 t MS/ ha) sobre outros cultivares, como o cv. Taiwan A-25 (2 t MS/ha), em dois cortes realizados no ano de estabelecimento. No ano seguinte, à semelhança do que foi verificado neste estudo, também foi observada redução na produção de forragem, atribuída às condições climáticas, em especial, à estação seca. Almeida \& Flaresso (1993), no Alto Vale do Itajaí, em Santa Catarina, destacaram a excelente produção de forragem do cv. Mineiro X-23A (28 t MS/ha/ano) em relação à produzida pelo cv. Cameroon (21 t MS/ha), 


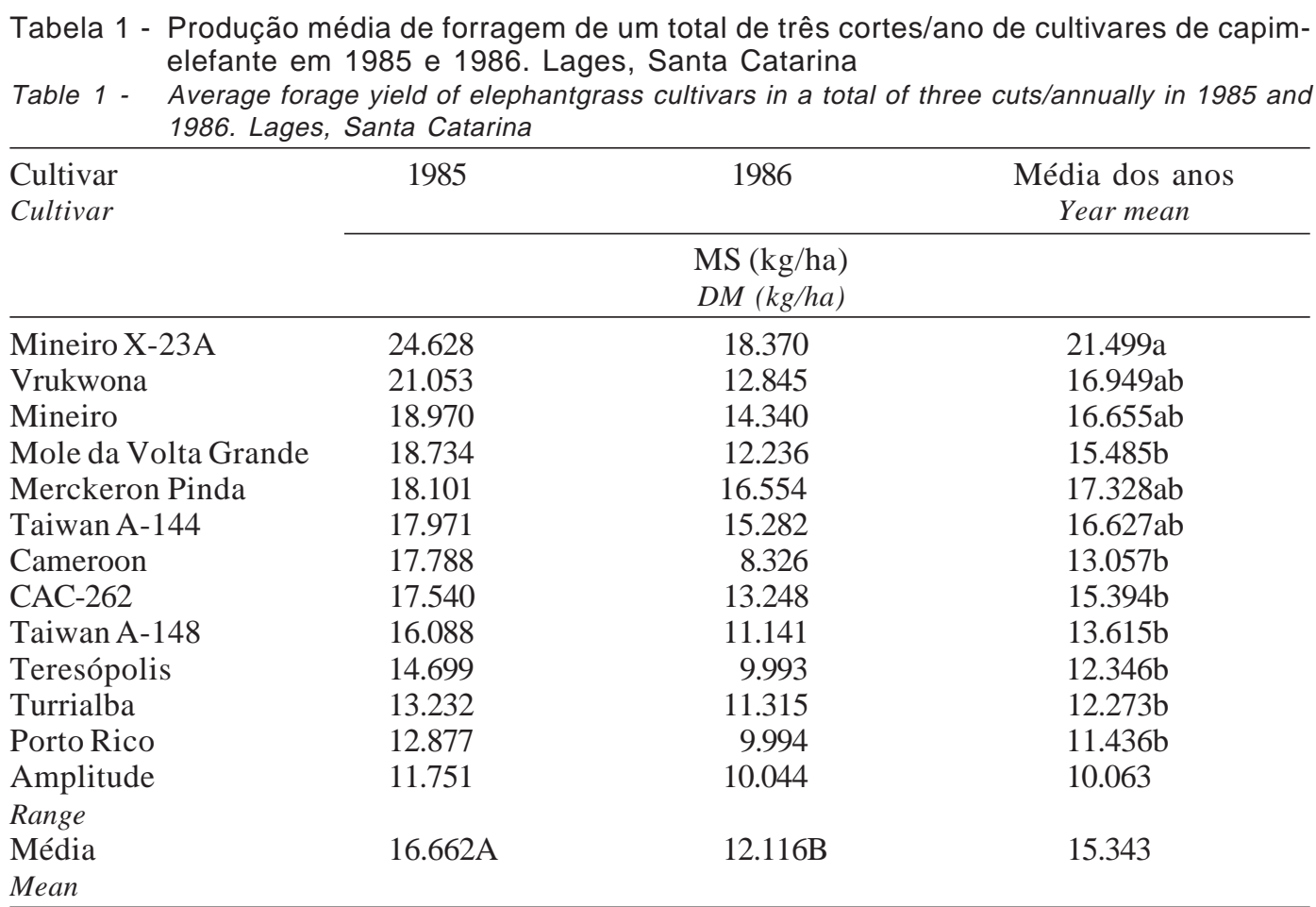

Médias seguidas de mesma letra minúscula, na coluna, e maiúscula, na linha, não diferem $(P>0,05)$ pelo teste Tukey.

Means followed by the same letter (small) in the column and in the row (capital) do not differ $(P>.05)$ by Tukey test.

confirmando o desempenho desse cultivar em diferentes regiões do país. No brejo paraibano, Queiroz Filho et al. (1998) não obtiveram diferenças entre produções anuais dos cultivares Cameroon (15t MS/ha), Gramafante (17,1 t MS/ha), Mineirão (18,8 t MS/ha) e Roxo (18,9 t MS/ha), avaliadas entre 1992 e 1995.

Com relação à produção estacional, apenas para os cortes de janeiro, verificou-se interação significativa $(\mathrm{P}<0,05)$ entre cultivares e anos (Figura 2$)$. A maioria dos cultivares mostrou redução na produção de forragem no segundo ano, com exceção dos cvs. Taiwan A-144, Merckeron, Porto Rico e Turrialba. Para os cultivares que se destacaram no primeiro ano, com produções acima de 10 t MS/ha em janeiro, a maior redução foi observada no cv. Cameroon $(85 \%)$ e a menor, no cv. Mineiro X-23A $(41 \%)$, sugerindo melhor adaptação às condições climáticas regionais.

Considerando-se as produções obtidas nas diferentes épocas do ano, observou-se decréscimo gradual de janeiro para maio e de forma mais evidente no primeiro ano (Tabela 2), o que provavelmente está vinculado à redução das temperaturas, especialmente a partir de março, característica do outono nessa região. Na média dos dois anos, as temperatura médias decresceram

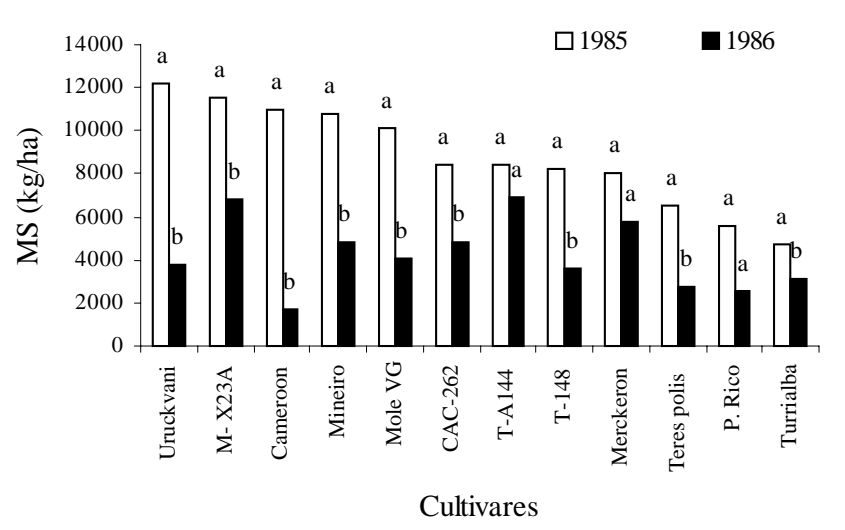

Figura 2 - Produção de forragem de cultivares de capim elefante em janeiro de 1985 e 1986.

Figure 2 - Forage yield of elephantgrass cultivars in January 1985 and 1986.

de $19,4^{\circ} \mathrm{C}$, em março, para $13,1^{\circ} \mathrm{C}$, em maio.

Por outro lado, a menor produção obtida em janeiro do segundo ano pode ser parcialmente creditada às baixas precipitações ocorridas entre o último corte de 1985 e o primeiro corte de 1986, em geral, abaixo da normal (Figura 1), indicando um período seco. Além disso, os boletins da Estação Meteorológica 
Tabela 2 - Produção de forragem de capim-elefante nos cortes realizados nos anos de 1985 e 1986. Lages, Santa Catarina

Table 2 - Forage yield of elephantgrass cultivars in 1985 and 1986 by date. Lages, Santa Catarina

\begin{tabular}{|c|c|c|c|c|c|c|}
\hline \multirow{3}{*}{$\begin{array}{l}\text { Cultivar } \\
\text { Cultivar }\end{array}$} & \multicolumn{3}{|c|}{1985} & \multicolumn{3}{|c|}{1986} \\
\hline & $10 / 01$ & $12 / 03$ & $3 / 05$ & $8 / 01$ & $5 / 03$ & $13 / 05$ \\
\hline & \multicolumn{6}{|c|}{$\begin{array}{l}\text { MS (kg/ha) } \\
D M(k g / h a)\end{array}$} \\
\hline Vrukwona & $12.167 \mathrm{a}$ & $6.675 \mathrm{ab}$ & $2.211 b c$ & $3.758 \mathrm{~ns}$ & $5.854 \mathrm{ab}$ & $3.233 \mathrm{ab}$ \\
\hline Mineiro X-23A & $11.523 \mathrm{ab}$ & $9.480 \mathrm{a}$ & $3.625 a$ & 6.829 & $6.633 \mathrm{ab}$ & $4.908 \mathrm{a}$ \\
\hline Cameroon & $10.937 \mathrm{ab}$ & $5.442 \mathrm{~b}$ & $1.409 \mathrm{c}$ & 1.673 & $4.088 b$ & $2.564 b$ \\
\hline Mineiro & $10.803 \mathrm{ab}$ & $5.814 b$ & $2.353 b c$ & 4.863 & $6.486 \mathrm{ab}$ & $2.992 b$ \\
\hline Mole V. Grande & $10.169 \mathrm{ab}$ & $6.234 \mathrm{ab}$ & $2.331 b c$ & 4.113 & $4.913 b$ & $3.211 \mathrm{ab}$ \\
\hline CAC-262 & $8.446 a b c$ & $6.998 \mathrm{ab}$ & $2.095 b c$ & 4.836 & $5.359 \mathrm{~b}$ & $3.053 \mathrm{~b}$ \\
\hline Taiwan A144 & $8.414 \mathrm{abc}$ & $7.405 \mathrm{ab}$ & $2.152 b c$ & 6.903 & $5.118 b$ & $3.261 \mathrm{ab}$ \\
\hline Taiwan 148 & $8.265 \mathrm{abc}$ & $5.263 b$ & $2.560 \mathrm{~b}$ & 3.619 & $4.157 b$ & $3.366 \mathrm{ab}$ \\
\hline Merckeron & $8.069 \mathrm{abc}$ & $7.989 \mathrm{ab}$ & $2.043 b c$ & 5.807 & $9.001 \mathrm{a}$ & $1.745 b$ \\
\hline Teresópolis & $6.529 \mathrm{abc}$ & $5.882 b$ & $2.288 b c$ & 2.702 & $4.825 b$ & $2.466 b$ \\
\hline Porto Rico & $5.583 \mathrm{bc}$ & $4.920 \mathrm{~b}$ & $2.375 \mathrm{ab}$ & 2.529 & $4.824 b$ & $2.641 b$ \\
\hline Turrialba & $4.714 \mathrm{c}$ & $5.439 b$ & $3.078 \mathrm{ab}$ & 3.141 & $5.675 \mathrm{ab}$ & $2.499 b$ \\
\hline Média & $8.802 \mathrm{~A}$ & $6.462 \mathrm{~A}$ & $2.377 \mathrm{~B}$ & $4.231 \mathrm{~B}$ & $5.578 \mathrm{~A}$ & $2.995 \mathrm{~A}$ \\
\hline
\end{tabular}

Médias seguidas de mesma letra minúscula, na coluna, e de mesma letra maiúscula na linha comparando os mesmos meses nos dois anos, não diferem $(P>0,05)$ pelo teste Tukey.

Means followed by the same letter in the column (small) and in the row (capital) comparing the same months in the two years did not differ $(P>.05)$ by Tukey test.

de Lages indicaram que apenas em maio de 1985 ocorreram oito geadas, seguidas de mais oito até setembro, o que seguramente impôs uma condição de estresse térmico às plantas. No entanto, essa condição foi importante e providencial para o propósito deste estudo, no qual cinco cultivares se destacaram, com produções acima de $3 \mathrm{t} \mathrm{MS} / \mathrm{ha}$, em especial o cv. Mineiro X-23A, com produção de $4.908 \mathrm{~kg}$ MS/ha (Tabela 2), em uma rebrota de 71 dias, ou seja, com taxa de crescimento de $69 \mathrm{~kg} \mathrm{MS} / \mathrm{ha} / \mathrm{dia}$, o que indica uma excelente alternativa forrageira para essa época, conhecida como vazio outonal na região sul.

Para os cortes realizados em maio, observou-se efeito significativo da interação cultivares $\mathrm{x}$ anos na produção de massa seca de folhas, sendo que as alterações foram significativas $(\mathrm{P}<0,05)$ para os cultivares Uruckvani e Cameroon, com aumento na produção, ao contrário do que se verificou com o cv. Turrialba (Figura 3). Destaca-se a expressiva produção de folhas do cv. Mineiro X-23A, com média de $3.428 \mathrm{~kg} \mathrm{MS} / \mathrm{ha}$, indicando taxa de produção de folhas de $56 \mathrm{~kg} \mathrm{MS/ha/dia,} \mathrm{em} \mathrm{uma} \mathrm{época} \mathrm{em} \mathrm{que} \mathrm{as}$ forrageiras anuais de inverno ainda não estão em condição de pastejo e as espécies de verão já completaram seu ciclo produtivo.

A produção de forragem dos cultivares esteve associada à estatura (Tabela 3), confirmando observa-

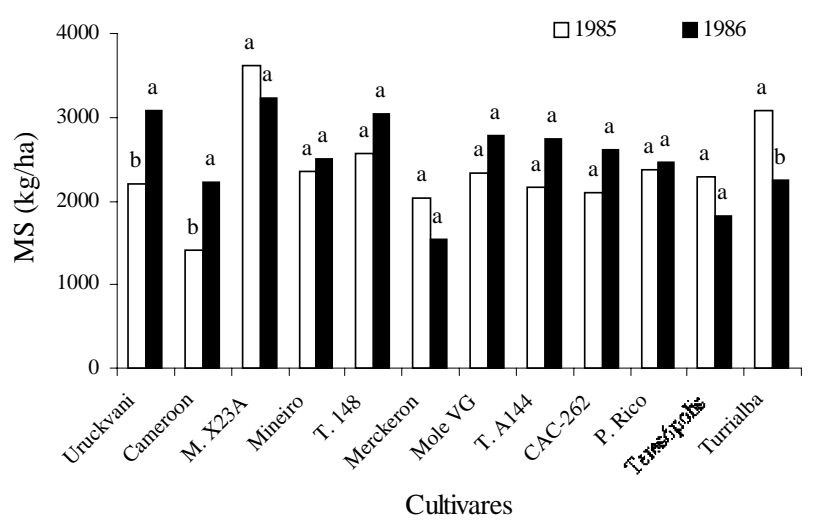

Figura 3 - Produção de massa seca folhas de cultivares de capim-elefante nos cortes de maio de 1985 e 1986.

Figure 3 - Leaf dry matter yield of elephant grass cultivars in cuts of May 1985 and 1986.

ções de outros pesquisadores (Santos et al.,1994; Mello et al., 2002). Segundo Coser et al. (1998), a estatura é um bom parâmetro para a estimativa da produção em capim-elefante. Entretanto, esse parâmetro também está associado à baixa relação folha:caule, conforme destacado por Virguez (1966) e Botrel el al. (1994). Nesse sentido, cabe destacar o desempenho do cv. Vrukwona no presente trabalho, que, apesar de estar no grupo dos cultivares mais produtivos (Tabela 1 ), foi 
Tabela 3 - Estatura, percentual médio de folhas e seletividade média de cultivares de capimelefante. Lages, Santa Catarina

Table 3 - Height, percentage of leaves and average selectivity of elephant grass cultivars. Lages, Santa Catarina

\begin{tabular}{|c|c|c|c|c|c|}
\hline \multirow[t]{2}{*}{$\begin{array}{l}\text { Cultivar } \\
\text { Cultivar }\end{array}$} & \multicolumn{2}{|c|}{$\begin{array}{c}\text { Estatura }(\mathrm{m}) \\
\text { Height }\end{array}$} & \multicolumn{2}{|c|}{$\begin{array}{c}\text { Folhas (\%) } \\
\text { Leaves }\end{array}$} & $\begin{array}{c}\text { Seletividade } \\
(\mathrm{jan} / \mathrm{mar} / 1987) \\
* \text { Selectivity } \\
(\text { jan/mar/1987)* }\end{array}$ \\
\hline & 1985 & 1986 & 1985 & 1986 & \\
\hline Mineiro X-23A & $1,70 \mathrm{a}$ & $1,73 \mathrm{a}$ & $75,9 a b$ & 70,7 & $4,7 \quad \mathrm{a}$ \\
\hline Vrukwona & $1,57 \mathrm{ab}$ & 1,25 bcde & 85,8 a & 90,3 a & $3,3 \mathrm{ab}$ \\
\hline Mineiro & $1,56 \mathrm{ab}$ & $1,31 \mathrm{bc}$ & $79,0 \mathrm{ab}$ & 81,5 abcd & $4,7 \quad a$ \\
\hline Cameroon & $1,53 \mathrm{abc}$ & 1,23 bcde & $85,2 \mathrm{a}$ & $86,6 \mathrm{ab}$ & $3,3 \mathrm{ab}$ \\
\hline Mole V. Grande & $1,47 \mathrm{abcd}$ & 1,13 bcde & $77,8 \mathrm{ab}$ & $87,0 \mathrm{ab}$ & $3,7 \quad a b$ \\
\hline CAC-262 & 1,41 bcd & $1,26 \mathrm{bcd}$ & $78,4 a b$ & $82,2 \mathrm{abc}$ & $4,7 \quad \mathrm{a}$ \\
\hline Taiwan A-144 & $1,37 \mathrm{bcd}$ & $1,36 \mathrm{~b}$ & $79,1 \mathrm{ab}$ & $78,8 \mathrm{abc}$ & 5,0 a \\
\hline Taiwan A-148 & 1,34 bcd & 1,27 bcd & $83,1 \mathrm{ab}$ & 83,6 abc & $3,3 \quad a b$ \\
\hline Teresópolis & $1,33 \mathrm{bcd}$ & $1,08 \mathrm{cde}$ & $73,9 \mathrm{~b}$ & $75,4 \mathrm{~cd}$ & $3,3 \mathrm{ab}$ \\
\hline Merckeron Pinda & $1,33 \mathrm{bcd}$ & 1,19 bcde & $82,2 \mathrm{ab}$ & 83,2 abc & $4,3 \mathrm{a}$ \\
\hline Porto Rico & 1,30 & 1,00 & 86,4 a & $90,5 \mathrm{a}$ & 2,3 \\
\hline Turrialba & 1,26 & 1,02 & $85,3 \mathrm{a}$ & $89,0 \mathrm{ab}$ & $3,3 \mathrm{ab}$ \\
\hline Médias & $1,43 \mathrm{~A}$ & $1,24 \mathrm{~A}$ & $81,0 \mathrm{~A}$ & $83,2 \mathrm{~A}$ & 3,8 \\
\hline
\end{tabular}

Means

* Notas referentes à quantidade de forragem residual após pastejo: $1=100 \mathrm{~g}, 2=325 \mathrm{~g}, 3=550 \mathrm{~g}$, $4=775 \mathrm{~g}$ e $5=1000 \mathrm{~g}$ massa verde/parcela.

* Scores related to the quantity of residual forage after grazing: $1=100 \mathrm{~g}, 2=325 \mathrm{~g}, 3=550 \mathrm{~g}, 4=775 \mathrm{~g}$ and $5=100 \mathrm{~g}$ of fresh matter/plot.

Médias seguidas de mesma letra, minúscula na coluna e maiúscula na linha, não diferem pelo teste Tukey $(P>0,05)$.

Means followed by the same letter (small) in the column do not differ $(P>.05)$ by Tukey test.

um dos que apresentou o maior percentual de folhas.

O cultivar Porto Rico foi o que apresentou maiores valores para seletividade, ao passo que o cv. Taiwan A144 foi o de menor seletividade pelos animais (Tabela 3 ), o que pode estar vinculado, pelo menos parcialmente, ao percentual de folhas e ao próprio porte dos cultivares, uma vez que aqueles com menor estatura apresentaram maior percentual de folhas e foram os mais consumidos. Este resultado contraria as observações de Virguez (1966) de que os clones menos produtivos de capim-elefante normalmente possuem maior proporção de folhas, o que se reflete diretamente na qualidade da forragem disponível.

Em experimentos que são realizados cortes sucessivos e avaliações periódicas de cultivares ao longo do tempo, torna-se possível estimar parâmetros importantes, como a estabilidade (previsibilidade de genótipos em relação à melhoria do ambiente), indispensável para orientar os trabalhos de melhoramento (Cruz \& Regazzi, 1997) e que, segundo Daher et al. (2003), são raros em plantas forrageiras.

Pela análise de estabilidade e adaptabilidade
(Tabela 4), verificou-se que apenas os cultivares Vrukwona, Turrialba, Porto Rico e Cameroon foram significativamente diferentes de $1(\mathrm{P}<5,0)$, indicando que esses cultivares apresentaram a menor adaptabilidade, sendo que Vrukwona e Cameroon se adaptam melhor a ambientes com maior potencial produtivo (B>1), enquanto os cvs. Porto Rico e Turrialba, a ambientes com menor potencial produtivo $(\mathrm{B}<1)$. Entre os demais cultivares, nenhum diferiu de 1, indicando boa adaptabilidade geral, embora o cv. CAC-262 apresente o B mais próximo de 1,0.

A maioria dos cultivares mostrou boa estabilidade (Tabela 5), com desvios de regressão $\left(\mathrm{s}^{2} \mathrm{~d}\right)$ desprezíveis. O cultivar mais estável foi o cv. CAC-262, ao passo que aquele com menor estabilidade foi o cv. Merckeron Pinda. Os cultivares não estáveis, portanto, incluíram esse último e os cvs. Cameroon e Taiwan A-144.

Considerando o conjunto de dados obtidos, o potencial produtivo e variabilidade entre cultivares do capim-elefante foram evidenciados para as condições do Planalto Catarinense, o que indica a importância da continuidade dos estudos envolvendo o 
Tabela 4 - Parâmetros de adaptabilidade de cultivares de capim-elefante cultivados sob condições de clima frio. Lages, Santa Catarina, 1985/1986

Table 4 - Adaptability parameters of elephantgrass cultivars grown under cold climate conditions. Lages, Santa Catarina, 1986/1986

\begin{tabular}{lcccc}
\hline $\begin{array}{l}\text { Cultivar } \\
\text { Cultivar }\end{array}$ & $\begin{array}{c}\text { Média } \\
\text { Mean }\end{array}$ & Beta & $\mathrm{t}(\mathrm{B}=1)$ & $\begin{array}{c}\text { Probabilidade }(\%) \\
\text { Probability }(\%)\end{array}$ \\
\hline Mineiro X-23A & 7.166 & 1,18 & 1,18 & 23,55 \\
Merckeron & 5.776 & 1,16 & 0,73 & 52,75 \\
Vrukwona & 5.650 & 1,47 & 2,97 & $0,37 *$ \\
Mineiro & 5.552 & 1,23 & 1,46 & 14,26 \\
Taiwan A144 & 5.542 & 0,90 & $-0,57$ & 57,63 \\
Mole V. Grande & 5.162 & 1,15 & 0,94 & 64,80 \\
CAC-262 & 5.131 & 0,98 & $-0,12$ & 89,62 \\
Taiwan 148 & 4.538 & 0,82 & $-1,14$ & 25,42 \\
Cameroon & 4.352 & 1,40 & 2,55 & $1,15 *$ \\
Teresópolis & 4.115 & 0,75 & $-1,56$ & 11,57 \\
Turrialba & 4.091 & 0,42 & $-3,68$ & $0,04 *$ \\
Porto Rico & 3.812 & 0,57 & $-2,74$ & $0,68^{*}$ \\
\hline
\end{tabular}

${ }^{*} \mathrm{P}<5,0$.

Tabela 5 - Parâmetros de estabilidade de cultivares de capim-elefante cultivados sob condições de clima frio. Lages, Santa Catarina, 1985/1986

Table 5 - Stability parameters of elephantgrass cultivars grown under cold climate conditions. Lages, Santa Catarina, 1985/1986

\begin{tabular}{lcccc}
\hline $\begin{array}{l}\text { Cultivar } \\
\text { Cultivar }\end{array}$ & $\begin{array}{c}\text { Média } \\
\text { Mean }\end{array}$ & $\sigma_{\mathrm{d}}^{2}$ & $\mathrm{~F}$ & $\begin{array}{c}\text { Probabilidade }(\%) \\
\text { Probability }(\%)\end{array}$ \\
\hline Mineiro X-23A & 7.166 & -129.276 & 0,81 & 100 \\
Merckeron & 5.776 & 3.141 .505 & 5,42 & 0,04 \\
Vrukwona & 5.650 & 165.391 & 1,23 & 30,01 \\
Mineiro & 5.552 & -19.198 & 0,97 & 100 \\
Taiwan A144 & 5.542 & 1.030 .323 & 2,44 & 4,93 \\
Mole V. Grande & 5.162 & -272.736 & 0,61 & 100 \\
CAC-262 & 5.131 & -490.922 & 0,31 & 100 \\
Taiwan 148 & 4.538 & -300.593 & 0,58 & 100 \\
Cameroon & 4.352 & 1.223 .109 & 2,72 & 3,23 \\
Teresópolis & 4.115 & -351.038 & 0,51 & 100 \\
Turrialba & 4.091 & 350.251 & 1,49 & 20,80 \\
Porto Rico & 3.812 & -359.625 & 0,49 & 100 \\
\hline
\end{tabular}

desempenho animal.

\section{Conclusões}

Há variabilidade no desempenho produtivo e na seletividade entre cultivares de capim-elefante para a região de Lages, Santa Catarina, destacando-se como promissores o cv. Mineiro X-23A, pela elevada produção, o cv. Porto Rico, pela maior seletividade animal e o cv. CAC-262, pela estabilidade.

\section{Literatura Citada}

ALMEIDA, E.X.; FLARESSO, J.A. Forrageiras para o Alto

Vale do Itajaí. Florianópolis: EPAGRI, 1993. 37p. (Boletim Técnico, 65)

ASSIS, A.G. de. Produção de leite a pasto no Brasil. In: SIMPÓSIO
INTERNACIONAL SOBRE PRODUÇÃO ANIMAL EM PASTEJO, 1997, Viçosa, MG. Anais... Viçosa, MG: Universidade Federal de Viçosa, 1997. p.381-410.

BOTREL, M.A.; ALVIM, M.J.; MARTINS, C.E. Avaliação e seleção de cultivares de capim-elefante (Pennisetum purpureum Schum.) para pastejo. Revista Brasileira de Zootecnia, v.23, n.5, p.754-762, 1994.

COSER, A.C.; MARTINS, C.E.; ALVIM, M.J. et al. Altura da planta e cobertura do solo como estimadores da produção de forragem em pastagem de capim-elefante. Revista Brasileira de Zootecnia, v.27, n.4, p.676-680, 1998.

CRUZ, C.D.; REGAZZI, A.J. Modelos biométricos aplicados ao melhraomento genético. Viçosa, MG: Universidade Federal de Viçosa, 1997. 390p.

DAHER, R.F.; PEREIRA, M.G.; AMARAL JR., A.T. et al. Estabilidade da produção forrageira em clones de capim elefante (Pennisetum purpureum Schum.). Ciência 
Agrotécnica, v.27, n.4, p.788-797, 2003.

DAHER, R.F.; MORAES, C.F.; CRUZ, C.D. et al. Diversidade morfológica e isoenzimática em capim-elefante (Pennisetum purpureum Schum.). Revista Brasileira de Zootecnia, v.26, n.2, p.255-264, 1997.

EBERHART, S.A.; RUSSELL, W.A. Stability parameters for comparing varieties. Crop Science, v.6, p.36-40, 1966.

GONÇALVES, J.O.N. Informações básicas sobre solos, clima, vegetação, áreas agroecológicas homogêneas e centros de pesquisa, na região sul do Brasil. In: PUIGNAU, J.P. (Ed.) Introduccion, conservacion y evaluacion de germoplasma forrajero em el Cono Sur. Montevideo: IICA, 1990. p.187-198.

HODGSON, J. Nomenclature and definitions ingrazing studies. Grass and Forage Science, v.34, p.11-18, 1979.

JACQUES, A.V.A. Fisiologia do crescimento do capim-elefante. In: SIMPÓSIO SOBRE CAPIM-ELEFANTE. Anais... Juiz de Fora: Embrapa Gado de Leite, 1990. p.23-34.

MELLO, A.C.L.; LIRA, M.A.; BATISTA, J.C. et al. Caracterização e seleção de clones de capim-elefante (Pennisetum purpureum Schum.) na Zona da Mata de Pernambuco. Revista Brasileira de Zootecnia, v.31, n.1, p.30-42, 2002.

MOZZER, O.L.; CARVALHO, M.M.; ENRICH, E.S. Competição de variedades e híbridos de capim elefante (Pennisetum purpureum Schum.). Pesquisa Agropecuária Brasileira, v.5, p.395-403, 1970.

OTERO, J.R. Informações sobre algumas plantas forrageiras. 2ed. Rio de Janeiro: SAI, 1961. 334p.

QUEIROZ FILHO, J.L.; SILVA, D.S.; NASCIMENTO, I.S. et al. Produção de matéria seca e qualidade de cultivares de capim-elefante (Pennisetum purpureum Schum.). Revista
Brasileira de Zootecnia, v.27, n.2, p.262-266, 1998.

SANTOS, M.C.M.; TABOSA, J.N.; DIAS, F. et al. Comportamento de clones de capim-elefante e de híbridos de capim-elefante $\mathrm{x}$ milheto no Semi-Árido do Nordeste do Brasil. Pesquisa Agropecuária Brasileira, v.29, n.10, p.1609-1615, 1994.

SKERMAN, P.J.; RIVEROS, F. Gramíneas tropicales. Roma: FAO, 1992. 849p.

TCACENCO, F.A.; BOTREL, M.A. Identificação e avaliação de acessos e cultivares de capim-elefante. In: SIMPÓSIO SOBRE CAPIM-ELEFANTE, 2., 1990, Coronel Pacheco. Anais... Coronel Pacheco: Embrapa Gado de Leite, 1990. p.1-22.

VETTERLE, C.P.; SALERNO, A.R. Competição de 34 cultivares de Pennisetum purpureum com Setaria anceps "Taiwan A-89" e Panicum maximum "Tancharia". In: REUNIÃO ANUAL DA SOCIEDADE BRASILEIRA DE ZOOTECNIA, 20., 1983, Pelotas. Anais... Pelotas: Universidade Federal de Pelotas, 1983. p.403.

VIRGUEZ, O.G. Ensayo comparativo de 13 clones del pasto elefante (Pennisetum purpureum Schum.). In: INTERNATIONAL GRASSLANDCONGRESS, 9., 1965, São Paulo. Proceedings... São Paulo: Secretaria de Agricultura de São Paulo/Departamento de Produção Animal, 1966, v.1, p.929-038.

WESTPHALEN, S.L. Forrageiras de clima tropical e subtropical: zoneamento climático. In: Zoneamento agrícola, estudos básicos: programa de investimento integrado para o setor agropecuário. Porto Alegre. Governo do Estado do Rio Grande do Sul: 1975.

Recebido em: 11/02/04

Aceito em: 14/02/05 